\title{
FRECUENCIA DE PARASITOSIS INTESTINAL EN MUESTRAS DE LA POBLACION INFANTIL DE QUITO
}

\author{
Dra. MAGDALENA RHEA y Dr. JOSE CASTRO, Quito.
}

El parasitismo infantil tiene una amplia distribución en todo el mundo, con especialidad en países de zonas tropicales, subtropicales; y con menos frecuencia, en zonas templadas o frías.

El parásito que es un ser vivo, animal o vegetal, pasa una parte o la totalidad de su existencia en la superficie o interior de otro ser vivo, biológicamente más desarrollado que él y a expensas del cual se nutre constituyendo una amenaza constante para la salud del huésped y dando origen a las enfermedades parasitarias.

El parasitismo se encuentra muy generalizado en nuestro medio y varios factores se reconocen como determinantes de este hecho. La finalidad del presente trabajo fue la de realizar un estudio comparativo de la incidencia de parasitosis intestinal en dos grupos de niños, uno perteneciente a la clase media y otro, a la clase popular.

\section{MATERIALES Y METODO}

El grupo representativo de la clase media estuvo constituído por 250 niños asistentes al Jardín de Infantes "Mer- cedes Noboa"; en tanto que el segundo grupo estuvo formado por $256 \mathrm{ni}$ ños provenientes de hogares de escasos recursos económicos y asistentes a la Casa Maternal "Carolina Terán", adscrita a la Dirección General de Hogares de Protección Social.

De cada uno de estos niños fue tomada una muestra de heces, en la cual se realizó el examen coproparasitario respectivo.

\section{RESULTADOS}

Hemos encontrado una frecuencia elevada de niños parasitados, con uno, dos, tres o más parásitos. La mayor parte de estos niños presentan un estado de desnutrición apreciable, contrastando con un escaso porciento de niños no parasitados que claramente demuestran su buen estado físico e intelectual. Los resultados obtenidos se resumen en las Tablas I y II.

El mayor grado de infestación parasitaria hemos encontrado en la Casa Maternal Carolina Terán; indudablemente allí concurren niños de recursos 


\section{Tabla I}

INCIDENCIA DE PARASITOSIS INTESTINAL EN NIÑOS DE LOS JARDINES "MERCEDES NOBOA" y "CAROLINA TERAN" DE QUITO, 1963.

\begin{tabular}{llllll}
\hline & \multicolumn{1}{c}{$\begin{array}{c}\text { Niños de clase } \\
\text { media }\end{array}$} & $\begin{array}{c}\text { Niños de clase } \\
\text { popular }\end{array}$ \\
\hline & No & $\%$ & No & $\%$ \\
\hline $\begin{array}{l}\text { Negativos } \\
\text { Positivos }\end{array}$ & 77 & 30.8 & 48 & 18.75 \\
$\begin{array}{l}\text { Mono- } \\
\text { parasitados } \ldots\end{array}$ & 78 & 31.0 & 76 & 29.65 \\
$\begin{array}{l}\text { Poli- } \\
\text { parasitados } \ldots\end{array}$ & 95 & 38.2 & 132 & 51.6 \\
\hline Total & 250 & 100.0 & 256 & 100.0 \\
\hline
\end{tabular}

socio-económicos deficientes y muy malos.

La infestación de A. histolítica en el Carolina Terán, corresponde a un $50 \%$ y en el Mercedes Noboa a un 34,4\%.

De igual manera la infestación con otros parásitos, si bien no es elevada, pero sí de consideración.

Se deduce que los parásitos más frecuentes son la Ameba histolítica, la Giardia lamblia, el Ascaris y los Tricocéfalos. Desde luego hay que anotar que en algunos niños que el examen coprológico indicó presencia de ameba, no tenían antecedentes de colitis sanguinolenta. Así mismo, los tricocéfalos, salvo una muy fuerte parasitación, no ocasionan trastornos intestinales.
Tabla II

PARASITOS IDENTIFICADOS EN LOS EXAMENES COPROPARASITARIOS PERTENECIENTES A NIÑOS DE LOS JARDINES "MERCEDES NOBOA" y "CAROLINA TERAN", De Quito-1963

\begin{tabular}{|c|c|c|c|c|}
\hline \multirow{2}{*}{ Parásitos } & \multicolumn{2}{|c|}{ Merced. Noboa } & \multicolumn{2}{|c|}{ Carol. Terán } \\
\hline & & & & \\
\hline E. histolítica … .... & 87 & 34.4 & 123 & 50.0 \\
\hline Giardia lamblia .... & 58 & 23.2 & 66 & 25.8 \\
\hline H. ascaris & & & & \\
\hline lumbricoides ......... & 25 & 10.0 & 48 & 17.9 \\
\hline H. tricocéfalos ......... & 17 & 6.8 & 25 & 9.79 \\
\hline Tricomonas ............ & 28 & 11.2 & 16 & 6.2 \\
\hline H. Himenolepis nana & 5 & 2.0 & 20 & 7.7 \\
\hline Blastocystis hóminis & 23 & 9.2 & 14 & 5.5 \\
\hline 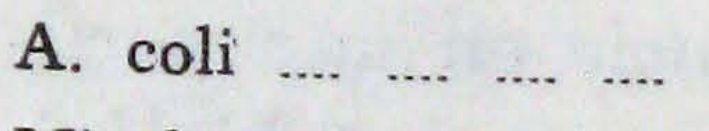 & 24 & 9.6 & 11 & 4.3 \\
\hline Micelios de hongos & 6 & 2.4 & 18 & 7.0 \\
\hline Endolimax nana & 6 & 2.4 & 7 & 2.7 \\
\hline Cercomonas …......... & 1 & 0.4 & & 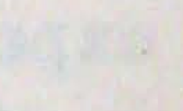 \\
\hline $\begin{array}{l}\text { Tenias (solium y } \\
\text { saginata) }\end{array}$ & 3 & 1.2 & & \\
\hline Chilomastix mesnilii & 5 & 2.0 & 5 & 1.9 \\
\hline
\end{tabular}

\section{DISCUSION}

Factores determinantes de la elevada incidencia de parasitosis intestinal en nuestro medio.

Según estadísticas y datos tomados de estudios realizados en nuestro país, un buen por ciento de la mortalidad infantil se debe a enfermedades infecciosas y otras son secundarias a desnutrición y parasitismo. Nuestro país tiene un índice de mortalidad infantil muy elevado, índice que nos da la me- 
dida de las condiciones sanitarias y socio-económicas de nuestra región. $\mathrm{Na}$ turalmente, estas condiciones son siempre mejores en las áreas urbanas en relación con las zonas rurales, pues en estas últimas hay un bajo nivel de educación sanitaria y cultural.

En la ciudad de Quito, podemos analizar las condiciones sanitarias teniendo en cuenta tres sectores: sur, central o comercial y norte o residencial. La distribución demográfica en estos tres sectores es marcadamente desigual con respecto al perímetro o zona que ocupan. Así, el sector sur, densamente poblado por miles de familias de recursos económicos reducidos, ocupa una área urbana relativamente pequeña. Los problemas más comunes en esta área son: estrechez de la vivienda, falta de servicios higiénicos, falta de canalizaciones y falta de agua potable, pues hay escasez de la misma en los sectores superpoblados.

El sector central está ocupado principalmente por el comercio de la ciudad; el problema higiénico en este sector radica en la presencia de los vendedores ambulantes. En estos últimos años se observa un considerable aumento de personas que se dedican al comercio de alimentos en sitios públicos y calles de la ciudad, contrariando las disposiciones del Código Sanitario de expendio de alimentos.

En Quito existen aproximadamente tres mil personas que realizan este comercio: son gentes de escasa cultura, que constituyen un verdadero peligro para la salud pública, afectando aún el ornato y dignidad de la ciudad.

El sector norte o residencial es el más amplio; el problema de la vivienda no está solucionado completamente, pero no presenta las condiciones deficientes del sector sur, la mayor parte de las familias viven en casas o apartamentos con buena iluminación, ventilación y condiciones higiénicas y sanitarias buenas.

Un aspecto fundamental en cuanto se refiere a la condición sanitaria de la ciudad, es la recolección de basura. En nuestro medio, el origen y por ciento de basuras recolectadas son las siguientes: transeuntes $10 \%$, vendedores ambulantes $20 \%$ y las que arrojan en vías públicas y que no fueron entregadas a los carros recolectores, $70 \%$.

La cantidad diaria de las basuras peligrosas que se recogen en las calles asciende a 600 quintales, cantidad sumamente elevada en comparación con las que producen otras ciudades. En ciudades alemanas el promedio anual por persona es de $1 / 2$ kilo y en Quito es de 25 kilos, o sea 50 veces más.

\section{RESUMEN}

Se realizó un estudio comparativo de la incidencia de parasitosis intestinal en dos grupos de niños, de diferente condición económica: uno de la clase media y otro de la clase popular.

En los niños de la clase media se encontró $30,8 \%$ de casos negativos y $69,2 \%$ de positivos; frente a $18,75 \%$ de resultados negativos y $81,25 \%$ de positivos en los niños de la clase popular.

Los parásitos más frecuentes, en orden de importancia, fueron los siguientes: A. histolítica, Giardia lamblia, As- 


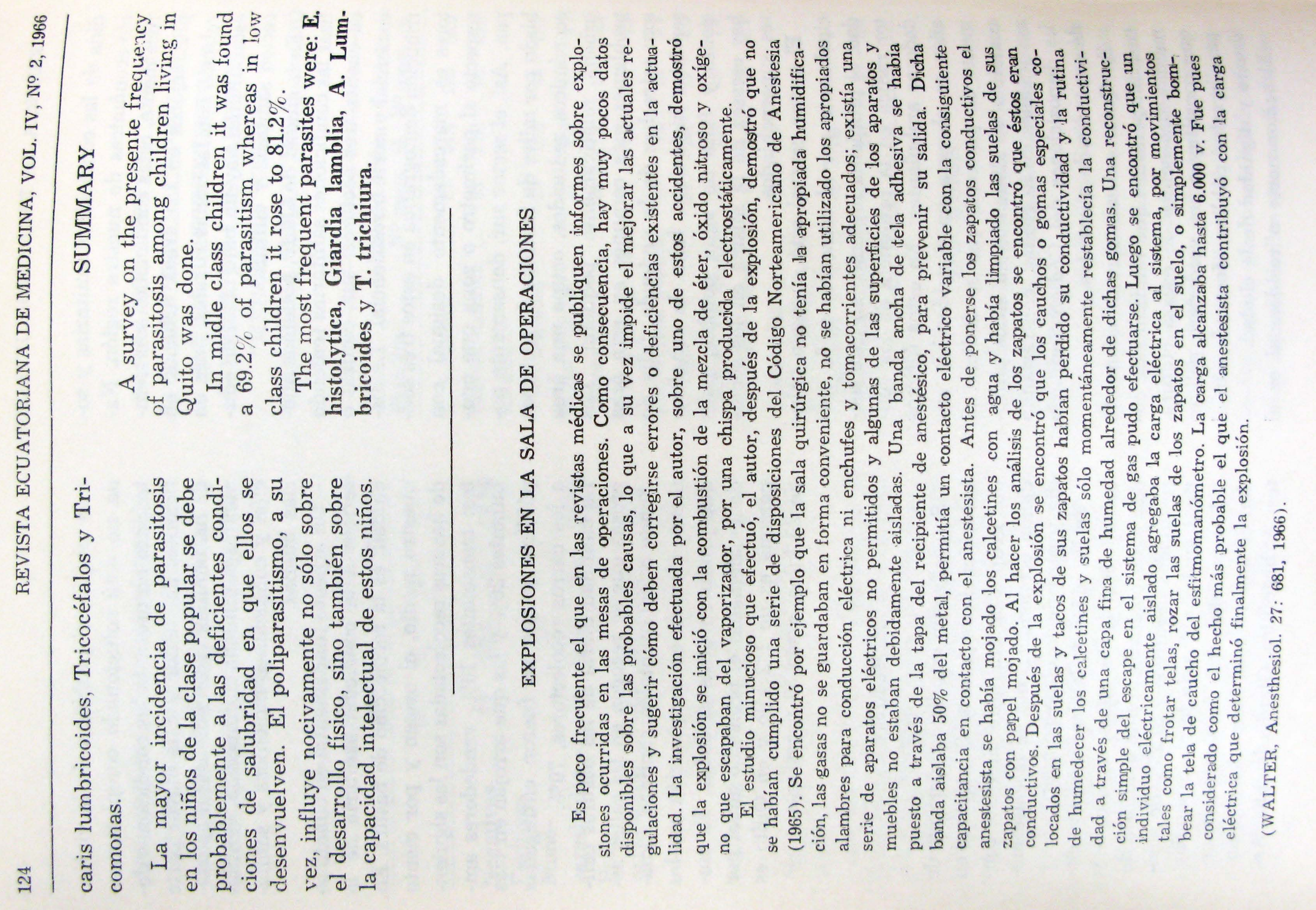

